\title{
Design of nanostructured siloxane-gelatin coatings: Immobilization strategies and dissolution properties
}

\author{
M. Martinez-Ibañez ${ }^{a, *}$, I. Aldalur ${ }^{a}$, F.J. Romero-Gavilán ${ }^{b}$, J. Suay ${ }^{b}$, I. Goñi ${ }^{a}$, M. Gurruchaga ${ }^{a}$ \\ ${ }^{a}$ Facultad de Ciencias Químicas, Universidad del País Vasco, P. M. de Lardizábal, 3, San Sebastián 20018, Spain \\ b Departamento de Ingeniería de Sistemas Industriales y Diseño, Universitat Jaume I, Av. Vicent Sos Baynat s/n, Castellón 12071, Spain
}

\section{A R T I C L E I N F O}

\section{Keywords:}

Hybrid material

Silicon

Gelatin

Dissolution mechanism

\begin{abstract}
A B S T R A C T
Owing to the outstanding service life of metallic prostheses, a substantial effort has been put into their surface modification to improve biocompatibility and reduce metallic ion diffusion. To satisfy these requirements, the coating materials obtained using the sol-gel method, with its wide range of tuning properties, have been extensively explored. The well-known biocompatibility of these materials makes them good candidates for different biomedical applications. We designed a series of siloxane-gelatin hybrids to be used as coatings for metallic implants or in controlled delivery systems. Two different matrixes were designed based on methyltrimethoxysilane (MTMOS), tetraethoxysilane (TEOS) and 3-glycidoxypropyltrimethoxysilane (GPTMS) alkoxysilane precursors. In one hybrid coating gelatin was physically entrapped and in the other it was linked to the siloxane network by covalent bonds. Synthesis parameters were established by studying the sol-gel reaction using ${ }^{29} \mathrm{Si}$ nuclear magnetic resonance $\left({ }^{29} \mathrm{Si} \mathrm{NMR}\right)$, which also allowed quantification of the network connectivity. Dissolution and degradation studies showed the effectiveness of GPTMS as a covalent coupling agent between the silica and gelatin phases; it increased the stability of the coatings in aqueous media. The aim of this study was to design a set of hybrid materials with highly tailorable properties, suitable for their potential biomedical applications.
\end{abstract}

\section{Introduction}

Metals like stainless steel, cobalt-chromium-based alloys, titanium or titanium alloys are the materials most widely used in the production of biomedical devices for the repair or replacement of hard tissue and load-bearing bone. Approximately $70 \%$ of the structural materials used in implants (artificial joints, bone plates, bone screws, and artificial tooth roots) are metallic. These metals have outstanding mechanical properties and long service life; they are resistant to corrosion and are biocompatible [1]. However, they are quite inert and lack bio-functionality (such as bone conductivity) and bioactivity [2]. Moreover, some studies have demonstrated that metallic ions can diffuse from the implant surface to surrounding tissues, with detrimental effects [3-5]. Hence, a substantial effort has been put into the design of surface modification of metal-based biomaterials. Bioactive ceramics or polymers have been used to develop bio-functional implants and coatings, avoiding the release of harmful metallic particles.

Calcium phosphate coatings have been used to obtain active surfaces because their chemical content resembles the mineral composition of the bone. Metal implants have been coated with inorganic compounds of this type. These compounds are mainly composed of hydroxyapatite (HA), which has bioactive and osteoinductive properties. The osseointegration of such coated implants is faster than of uncoated metal devices [6]; however, the weak adhesion between the HA layer and the metal surface constitutes a critical limitation $[7,8]$. Some clinical problems have been associated with the failure of adhesion [9].

The demand for alternative methodologies for coating metallic implants has created a widespread interest in the use of sol-gel synthesis route due to their numerous advantages over other coating methods, such as low energy consumption and corrosion protection $[10,11]$. The silicon alkoxides have been most thoroughly studied among the available metalloid alkoxide precursors. They are widely used in the development of sol-gel biomaterials, mostly due to their recognized biocompatibility and osteoregenerative properties. Therefore, sol-gel route has been widely used in the field of biomaterials for the obtaining of hybrid materials that give rise to monoliths, fibers, powders or films with a wide variety of characteristics [12]. Interestingly, this method allows the deposition of homogeneous coatings on substrates of large and complex curved shapes, by means of various coating methods such as dip-coating, flow-coating or spray coating [13]. Moreover, during

\footnotetext{
* Corresponding author.

E-mail address: mmartinez@cicenergigune.com (M. Martinez-Ibañez).
} 
drying and curing step of the sol-gel process, strong covalent metallosiloxane bonds are created, resulting in excellent adhesion between solgel coatings and metal surfaces [14].

TEOS is one of the precursors most often used in the synthesis of bioactive inorganic sol-gel materials [15]. There is also a growing interest in the use of organically modified silicates to obtain hybrid materials with improved properties. Beganskiene et al. [16] have prepared and characterized modified sol-gel derived silica coatings. They have introduced the amino and methyl groups onto the colloidal silica using (3-aminopropyl) triethoxysilane (APTES) and MTMOS, respectively. They have found that the methyl-modified coating is the best substrate supporting cell proliferation. Juan-Diaz et al. [17] have developed functionalized sol-gel coatings by mixing MTMOS and GPTMS (which possesses an epoxide ring) in different molar ratios to improve the osseointegration of titanium implants. The hybrid made using a 1:1 MTMOS:GPTMS ratio showed the best proliferation and mineralization rate. Similarly, hybrids based on MTMOS and TEOS alkoxysilanes improve the mesenchymal stem cells differentiation; this effect increases with the increasing content of the TEOS precursor [18].

The current trends in biomaterials focus on the incorporation of different biomolecules into synthetic polymeric matrixes to mimic the native extracellular matrix (ECM) and regulate the cell behavior. Collagen is the main constituent of native ECM; this protein has been widely used in the pharmaceutical and medical fields. Nevertheless, collagen-containing materials usually suffer from poor physicochemical properties and also have some drawbacks from the material processing point of view [19]. Thus, gelatin replaced collagen in many applications. Most of the recent studies have chosen gelatin because of its biodegradability and bioadhesive properties. Mahony et al. have designed [20] some silica-gelatin scaffolds; these scaffolds have various applications in both hard and soft tissues as their properties can be individually tailored. Lim et al. [21] have incorporated gelatin into a modified polyvinyl alcohol (PVA) hydrogel. This addition does not alter the physical and mechanical properties of the polymer, but significantly improves the cellular interactions. Similarly, Shi et al. [22] have found that gelatin, when grafted onto polycarbonate urethane scaffolds, increases the cell growth and proliferation. The immobilization of such biomolecules can be achieved using: (i) entrapment in the polymeric matrix or (ii) covalent attachment to a polymer carrying pendant reactive groups.

In previous papers $[23,24]$, we reported the benefits of some gelatin/sol-gel coatings on the osteogenesis capability of coated dental implants and the importance of the chemical composition and structure of the material on the release of $\mathrm{Si}$ and gelatin. With the aim to go in depth through the knowledge of the synthesis possibilities on the obtaining of formulations with $\mathrm{Si}$ and gelatin release modulation capacity, here, we report the synthesis of different gelatin-siloxane materials. Those materials were created using mixtures of three alkoxysilane precursors: MTMOS-TEOS coatings, with various amounts of physically entrapped gelatin, and MTMOS-GPMTS coatings with chemically anchored gelatin in various concentrations. Our objective was to examine the effect of incorporated gelatin on the characteristics of the siloxane network, such as the chemical structure and dissolution rate, focused on the potential applications as coatings for metallic biomaterials or as delivery matrixes.

\section{Materials and methods}

\subsection{Sol-gel films}

Organic-inorganic hybrid coatings were synthesized from MTMOS, GPTMS, TEOS and gelatin from porcine skin, Type A. All these reagents were purchased from Sigma-Aldrich and used without further purification. Based on previous studies described in full elsewhere [17,23], the molar ratio between the alkoxysilane precursors MTMOS and TEOS was $7: 3$ and the ratio for the matrix of MTMOS and GPTMS was 5:5. The
Table 1

Chemical composition of siloxane-gelatin coatings expressed as molar percentage of alkoxysilane precursors and gelatin weight percentage.

\begin{tabular}{lllll}
\hline Coating & MTMOS (\%) & GPTMS (\%) & TEOS (\%) & Gelatin (wt\%) \\
\hline 7M3T & 70 & - & 30 & - \\
7M3T-0.2 & 70 & - & 30 & 0.2 \\
7M3T-0.9 & 70 & - & 30 & 0.9 \\
7M3T-2.0 & 70 & - & 30 & 2.0 \\
5M5G & 50 & 50 & - & - \\
5M5G-0.2 & 50 & 50 & - & 0.2 \\
5M5G-0.9 & 50 & 50 & - & 0.9 \\
5M5G-2.0 & 50 & 50 & - & 2.0 \\
\hline
\end{tabular}

concentration of gelatin in the silica sol was varied $(0,0.2,0.9$ and $2.0 \mathrm{wt} \%$ ), giving rise to 8 different coatings (Table 1) named 7M3T, 5M5G, 7M3T-0.2, 5M5G-0.2, 7M3T-0.9, 5M5G-0.9, 7M3T-2.0 and 5M5G-2.0.

To obtain 7M3T and 5M5G coatings, the alkoxysilanes were mixed at the appropriate molar ratio, using 2-propanol (Sigma-Aldrich) as solvent (the volume ratio of alcohol to precursor was 1:1). A stoichiometric amount of hydrolyzing solution, an aqueous solution of hydrochloric acid ( $\mathrm{HCl}, \mathrm{pH} \mathrm{1),} \mathrm{was} \mathrm{added} \mathrm{drop-wise} \mathrm{as} \mathrm{the} \mathrm{catalyst} \mathrm{of} \mathrm{the}$ reaction. The solution was stirred for $2 \mathrm{~h}$ to achieve the sol-gel polymerization. For hybrids with gelatin, a mixture of isopropanol and water $(1: 1 \mathrm{v} / \mathrm{v})$ was used as a solvent to ensure a good miscibility to obtain a homogeneous sol.

The sols were applied onto different substrates. To obtain free films, $3 \mathrm{~mL}$ of each sol was poured into a non-stick Teflon mold. The films were used for the chemical characterization of each material. To determine the hydrophilicity of the surface and for the dissolution study, the stainless steel AISI $316-\mathrm{L}$ plates $(5 \times 5 \mathrm{~cm}$, RNSinox, S.L.) were used as substrate. The plates were polished and cleaned with acetone to remove impurities. After cleaning, the plates were immersed in the sol using a dip-coater (KSV instrument KSV DC) at the speed of $60 \mathrm{~mm} \mathrm{~min}^{-1}$, left for $1 \mathrm{~min}$, and removed at $100 \mathrm{~mm} \mathrm{~min}^{-1}$. Then, the plates were heated to obtain a condensed and solid surface $\left(80^{\circ} \mathrm{C}\right.$ and $100{ }^{\circ} \mathrm{C}$ for $2 \mathrm{~h}$, for 7M3T and 5M5G series hybrids, respectively).

\subsection{Chemical characterization}

The sol-gel reaction was studied using the liquid state ${ }^{29} \mathrm{Si}$ NMR. The technique was employed to follow the hydrolysis and condensation reaction of the siloxane network. The spectra were recorded on a FTNMR Bruker 400 Avance spectrometer, at 79.47 MHz. The pulse length was $10 \mathrm{~ms}$, acquisition time $2 \mathrm{~s}$, and the number of scans 384 .

Chromium acetylacetonate, $\mathrm{Cr}(\mathrm{acac})_{3}$ was added to the reaction mix at a concentration of $2.5 \times 10^{-3} \mathrm{M}$ as a spin relaxation agent [25]. The external lock solvent was methanol- $d_{4}$, and the spectra were referenced to tetramethyl silane. The reaction mixture was prepared, and spectra were recorded before and after adding the catalyst, for up to $2 \mathrm{~h}$.

The solid-state ${ }^{29} \mathrm{Si}$ NMR spectroscopy was used to determine the final structure of the siloxane network and the Si-O-Si cross-linking density achieved after the curing of the films. Cross Polarization Magic Angle Spinning (CP-MAS) NMR spectra were recorded on a 9.4 T Bruker $400 \mathrm{MHZ}$ Avance III WB PLUS spectrometer at $79.5 \mathrm{MHz}$. Powdered samples were placed in 4-mm rotor tubes. For the spectra acquisition, we used the sample spinning speed of $10 \mathrm{kHz}$, spectral width of $30 \mathrm{kHz}$, contact time of $2 \mathrm{~ms}$, and delay time of $5 \mathrm{~ms}$. Peak fitting was employed to determine the relative abundance of each type of silicon atom, $T$ and $\mathrm{Q}$ species. Using these data, the network connectivity was quantified and expressed as a degree of condensation $\left(D_{C}\right)$ (Eq. (1)):

$D_{C}=\frac{4 \mathrm{Q}^{4}+3 \mathrm{Q}^{3}+2 \mathrm{Q}^{2}}{4}+\frac{3 \mathrm{~T}^{3}+2 \mathrm{~T}^{2}}{3}$

where $\mathrm{Q}^{\mathrm{n}}$ represents the abundance of a silicon atom bound to $n$ 
bridging oxygen atoms (TEOS), and $\mathrm{T}^{\mathrm{n}}$ a silicon atom bound to one carbon and $n$ bridging oxygen atoms (MTMOS and GPTMS). The spectra obtained in the liquid state allow distinguishing between the $\mathrm{T}$ species of the MTMOS and GPTMS precursors, designated as $\mathrm{T}_{\mathrm{M}}$ and $\mathrm{T}_{\mathrm{G}}$ respectively.

Fourier-transform infrared (FTIR) spectroscopy (using FTIR 6700 Nicolet spectrometer) was also used to characterize the structure of obtained films. The spectra were recorded in the attenuated total reflectance mode and the wavenumbers ranged between 4000 and $400 \mathrm{~cm}^{-1}$

\subsection{Topography analysis}

Surface topography was studied employing atomic force microscopy (AFM). The nanoscale surface roughness of the coating was characterized using the non-contact tapping mode AFM (Nanoscope III Multimode AFM, Bruker). Etched silicon TESP-V2 probes with force constant of approximately $42 \mathrm{~N} / \mathrm{m}$ and a resonance frequency of $320 \mathrm{~Hz}$ were used. Images were collected at a frequency of $1 \mathrm{~Hz}$ and angle of $0^{\circ}$. Five randomly distributed areas of each surface were analyzed employing the NanoScope Analysis 1.5 software. Roughness was reported as the mean roughness $(\mathrm{Ra})$

\subsection{Hydrophilic/hydrophobic nature}

The wettability was determined by measuring the contact angle of deionized water on the different surfaces, using an automatic goniometer (DataPhysics OCA 20). The test was carried out at room temperature; a sessile drop of $10 \mu \mathrm{L}$ of deionized water was placed on the coated surfaces. The reported values are the means of at least 9 measurements.

\subsection{Dissolution study}

\subsubsection{Gravimetric degradation}

The polysiloxane network hydrolyzes in aqueous media as follows (Eq. (2)):

$\mathrm{SiO}_{2}(\mathrm{~s})+2 \mathrm{H}_{2} \mathrm{O} \rightarrow \mathrm{Si}(\mathrm{OH})_{4}(\mathrm{aq})$

Hydrolytic degradation was evaluated using gravimetric measurements, comparing the weight of the coatings before and after soaking in phosphate buffer saline (PBS, Sigma-Aldrich) at $37^{\circ} \mathrm{C}$. The study was followed for up to 8 weeks. Each data point is an average of three individual measurements.

\subsubsection{Silicon release}

During the hydrolytic degradation of the coating, the Si compounds are released to the media. The Si release was studied using the samples submerged in PBS at $37^{\circ} \mathrm{C}$ for 8 weeks. Aliquots of $500 \mu \mathrm{L}$ were taken after 1, 2, 4 and 8 weeks of immersion. For the Si quantification, the inductively coupled plasma mass spectrometer Agilent 7700 Series ICPMS was used. Each data point is an average of three individual measurements.

\subsubsection{Gelatin release}

The amount of gelatin released during the degradation of the network was also examined. The coatings were immersed in $50 \mathrm{~mL}$ of PBS and left in an incubator at $37^{\circ} \mathrm{C}$ for up to 8 weeks. At each time point $1 \mathrm{~mL}$ sample was removed and analyzed for gelatin concentration using the QuantiPro ${ }^{\mathrm{TM}}$ BCA Protein Assay Kit (Sigma-Adrich). Each data point is the mean of three individual measurements.

\subsection{Statistical analysis}

For results analysis, mean and standard deviation values were calculated using the 1-way ANOVA statistical technique, using SPSS 17.

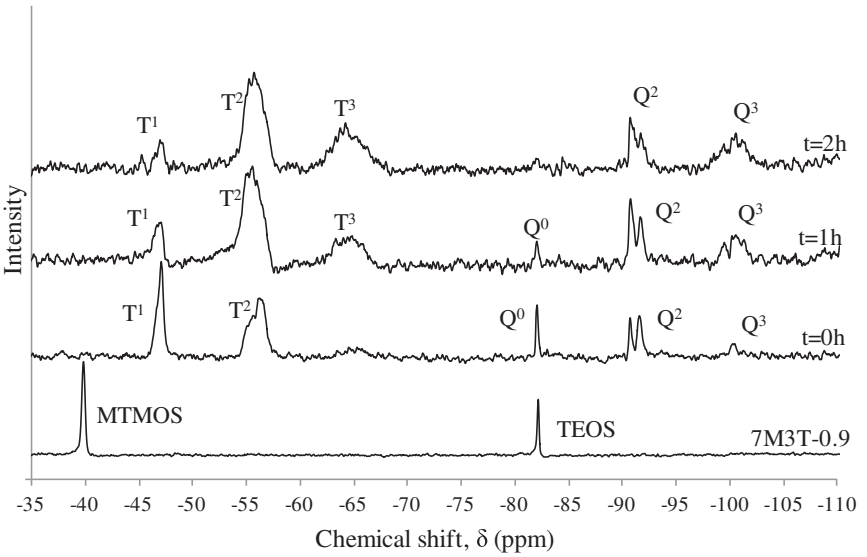

Fig. 1. Liquid state ${ }^{29} \mathrm{Si}$ NMR of sol-gel reaction process for 7M3T-0.9.

The error protection method used in this research was the Tukey HSD method and the confidence limit used was $95 \%$.

\section{Results}

\subsection{Chemical characterization}

The degree of the sol-gel reaction was examined using the ${ }^{29} \mathrm{Si}$ liquid NMR, for up to $2 \mathrm{~h}$. Fig. 1 shows the spectra obtained for the hydrolysis and condensation reactions for the 7M3T-0.9 hybrid (an example) Before the addition of the catalyst there were only two types of $\mathrm{Si}$ atoms, corresponding to the MTMOS ( $-40 \mathrm{ppm})$ and TEOS ( $-82 \mathrm{ppm})$ precursors. Then, the catalyst was added $(t=0)$ and the signals for the hydrolyzed and condensed species were obtained. The reaction takes place rapidly, increasing the peak intensity for the most condensed species $\left(\mathrm{T}^{2}, \mathrm{~T}^{3}\right.$ and $\mathrm{Q}^{3}$ ) and decreasing the peak intensity for the hydrolyzed and the least condensed species $\left(\mathrm{Q}^{0}\right.$ and $\left.\mathrm{T}^{1}\right)$. The same behavior was observed for all the studied materials; the sol-gel reactions proceeded increasing the cross-linking in the network.

The spectra obtained for 7M3T hybrids (with and without gelatin) using liquid-state ${ }^{29} \mathrm{Si}$-NRM after $2 \mathrm{~h}$ of reaction (Fig. 2) show the similar intensity of the signals attributed to each $\mathrm{Si}$ atom species, in all the cases. The connectivity of the silica network remains intact despite the introduction of the gelatin.

However, the comparison of the spectra of 5M5G hybrids with the different percentages of gelatin (Fig. 3) shows significant differences. In the case of the hybrid 5M5G without gelatin, all the MTMOS and GPTMS molecules started to condense due to the absence of $\mathrm{T}_{M}(\mathrm{OH})$ and $\mathrm{T}_{\mathrm{G}}(\mathrm{OH})$, respectively. Nevertheless, the introduction of gelatin

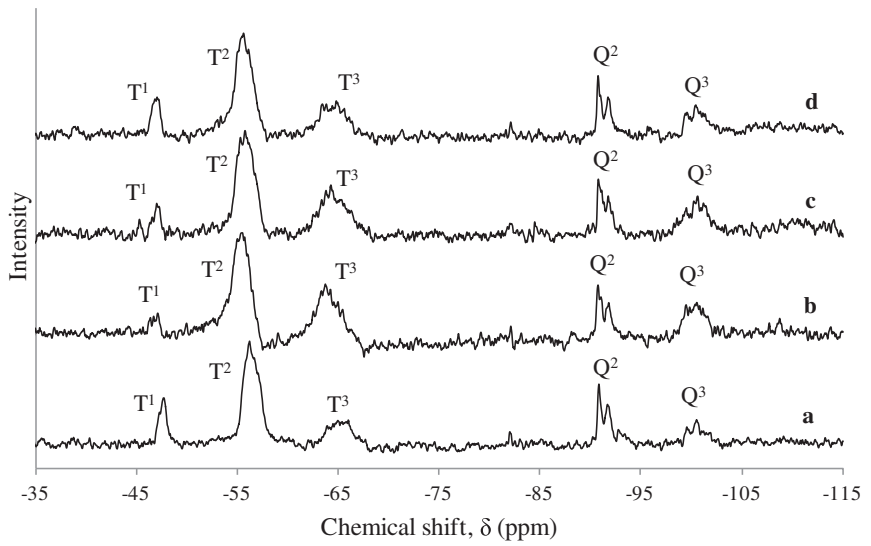

Fig. 2. Liquid state ${ }^{29} \mathrm{Si}$ NMR spectra of (a) 7M3T, (b) 7M3T-0.2, (c) 7M3T-0.9 and (d) 7M3T-2.0 after $2 \mathrm{~h}$ of reaction. 


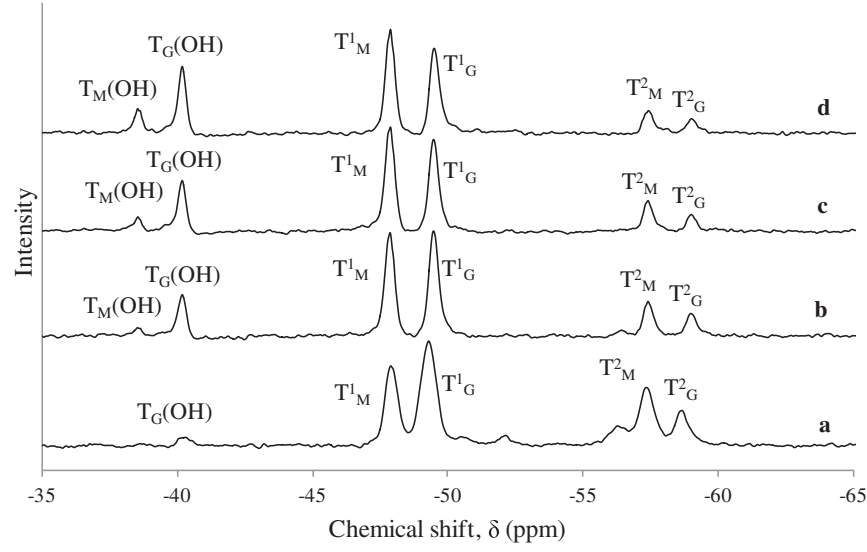

Fig. 3. Liquid state ${ }^{29} \mathrm{Si}$ NMR spectra of (a) $5 \mathrm{M} 5 \mathrm{G}$, (b) $5 \mathrm{M} 5 \mathrm{G}-0.2$, (c) $5 \mathrm{M} 5 \mathrm{G}-0.9$ and (d) $5 \mathrm{M} 5 \mathrm{G}-2.0$ after $2 \mathrm{~h}$ of reaction.

decreased the speed of the reaction, and after $2 \mathrm{~h}$ there were still some unreacted $\mathrm{T}_{\mathrm{M}}(\mathrm{OH})$ and $\mathrm{T}_{\mathrm{G}}(\mathrm{OH})$ species. Moreover, the signal intensity of those non-cross-linked molecules rose with the increase in the gelatin content. The abundance of the most cross-linked Si species, such as $\mathrm{T}_{\mathrm{M}}^{2}$ and $\mathrm{T}_{\mathrm{G}}^{2}$, decreased with the increasing of gelatin content.

After heat treatment, continuous films were obtained. Those films appeared free of cracks and with high adhesion strength, as demonstrated applying the cross-cut test [23]. To determine the total network connectivity, we studied the chemical structure of the hybrids after the aging and drying step using solid-state ${ }^{29} \mathrm{Si}$ NMR. The spectra shown in Fig. 4 prove the efficacy of the heat treatment. The treatment resulted in the formation of a cross-linked silica network, which was confirmed by the disappearance of $\mathrm{T}(\mathrm{OH})$ species and the formation of highly cross-linked species $\left(\mathrm{T}^{3}, \mathrm{Q}^{3}\right.$ and $\left.\mathrm{Q}^{4}\right)$. Moreover, our results revealed that 7M3T and 7M3T-2.0 hybrids (spectra a and b) had very similar inorganic structures, while 5M5G and 5M5G-2.0 (spectra c and d) showed significant differences.

The integration of the area of each peak gave the relative abundances of each $\mathrm{T}$ and $\mathrm{Q}$ species (Eq. (1)) and the total network connectivity expressed as Dc (Table 2). 7M3T and 7M3T-2.0 hybrids had similar inorganic structures with very slight differences between their relative molar percentages and degrees of condensation. 5M5G had the lowest $\mathrm{D}_{\mathrm{C}}$, which increased from $80.3 \%$ to $91.3 \%$ after adding gelatin.

Fig. 5 shows, as an example, the IR spectra of the sol-gel network

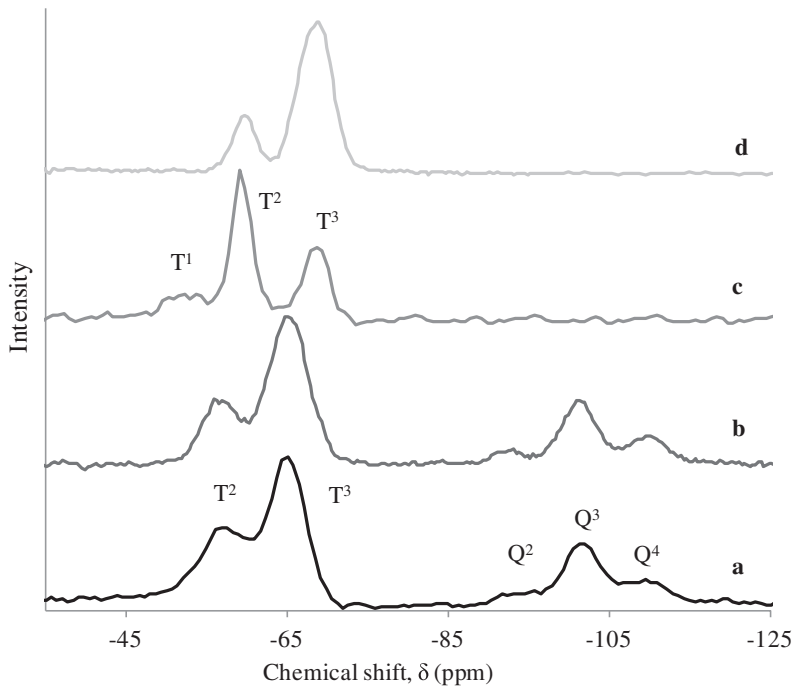

Fig. 4. Solid-state ${ }^{29}$ Si NMR spectra of (a) 7M3T, (b) 7M3T-2.0, (c) 5M5G and (d) 5M5G2.0 films after the heat treatment.
Table 2

Molar percentages of the species (obtained by ${ }^{29} \mathrm{Si}$ NMR) and the total network connectivity.

\begin{tabular}{lccccccc}
\hline Coating & $\mathrm{T}^{1}$ & $\mathrm{~T}^{2}$ & $\mathrm{~T}^{3}$ & $\mathrm{Q}^{2}$ & $\mathrm{Q}^{3}$ & $\mathrm{Q}^{4}$ & $\mathrm{D}_{\mathrm{C}}$ \\
\hline 7M3T & - & 20 & 43 & 3 & 22 & 12 & 86.3 \\
7M3T-2.0 & - & 21 & 43 & 3 & 22 & 11 & 86.0 \\
5M5G & 2 & 52 & 45 & - & - & - & 80.3 \\
5M5G-2.0 & - & 26 & 74 & - & - & - & 91.3 \\
\hline
\end{tabular}

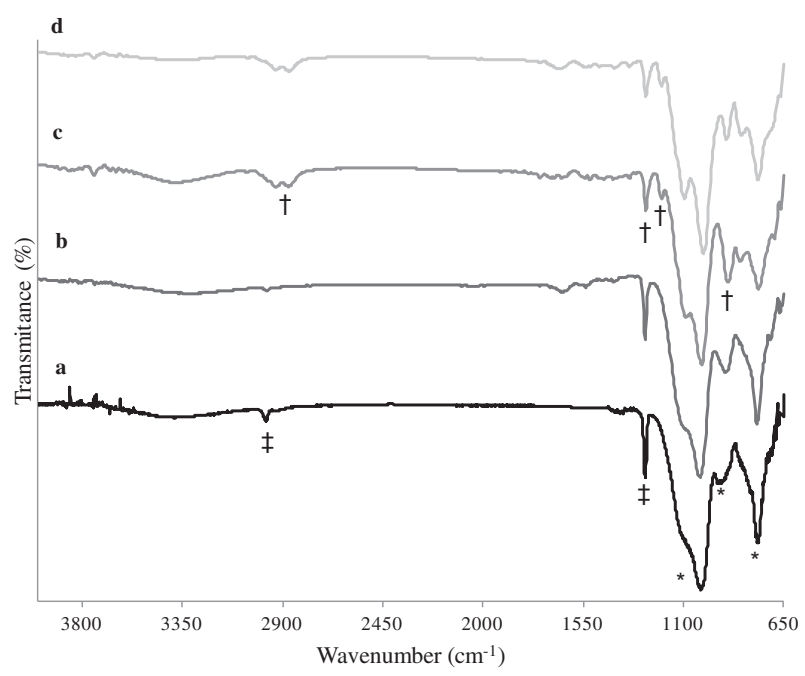

Fig. 5. FTIR spectra of (a) 7M3T, (b) 7M3T-2.0, (c) 5M5G and (d) 5M5G-2.0 coatings. * indicates the bands associated with the vibration of siloxane bonds; the characteristics vibration bands of MTMOS precursor; and $\dagger$, the bands associated with the GPTMS precursor.

obtained for 7M3T, 7M3T-2.0, 5M5G, and 5M5G-2.0 coatings. All the hybrids show the characteristic bands associated with the siloxane bond vibration (indicated in the spectra by asterisks), Si-O-Si, at $1100 \mathrm{~cm}^{-1}$, $1010 \mathrm{~cm}^{-1}$, and $780 \mathrm{~cm}^{-1}$; this last band overlaps with the vibration mode of the $\mathrm{Si}-\mathrm{C}$ bond which appears at $770 \mathrm{~cm}^{-1}[26,27]$. Coatings with MTMOS showed bands at $2975 \mathrm{~cm}^{-1}$ and $1280 \mathrm{~cm}^{-1}$, corresponding to the methyl group bound to the silicon atom. In addition, the silanol terminal groups ( $\mathrm{Si}-\mathrm{OH}$ ) were detected at $950 \mathrm{~cm}^{-1}$ in the case of 7M3T; this band was shifted to $900 \mathrm{~cm}^{-1}$ in the spectrum of the 7M3T-2.0 hybrid due to the introduction of gelatin. For 5M5G coatings, we found bands at $2950 \mathrm{~cm}^{-1}, 2860 \mathrm{~cm}^{-1}, 1280 \mathrm{~cm}^{-1}$, and $1200 \mathrm{~cm}^{-1}$, corresponding to the vibration of the methylene and methyl groups. Moreover, GPTMS shows two bands of absorbance close to 750 and $900 \mathrm{~cm}^{-1}$ due to the stretching of the C-O-C bond of the epoxide group. However, these bands are obscured by the silanol band, which also appears around this wavenumber [28]. The comparison of the signals of the epoxy ring (at $900 \mathrm{~cm}^{-1}$ ) for the 5M5G and 5M5G-2.0 hybrids (spectrum $\mathrm{c}$ and $\mathrm{d}$ ), shows a decrease in the intensity of the band after the introduction of gelatin.

\subsection{Surface characterization}

The wettability of the coatings was examined using contact angle measurements. The results are shown in Table 3. We observed that the introduction of gelatin in 7M3T hybrid caused a decrease in the contact angle, from $70.0^{\circ}$ to $52.6^{\circ}$, reflecting an increase in hydrophilicity. However, 5M5G hybrids did not show the same trend; a slight increase in the contact angle was observed after the introduction of gelatin.

The average surface roughness values ( $\mathrm{Ra}$ ) are also shown in Table 3. The topography of all the studied materials was in the nanolength scale. The AFM data (Ra values) for the 7M3T hybrids series reflect their rougher surface in comparison with the 5M5G hybrids; the 
Table 3

Contact angle and $\mathrm{Ra}$ values with their standard deviations.

\begin{tabular}{lll}
\hline Coating & Contact angle $\left(^{\circ}\right)$ & Ra (nm) \\
\hline 7M3T & $70.0 \pm 0.8$ & $0.50 \pm 0.20$ \\
7M3T-0.9 & $58.2 \pm 3.1$ & $0.43 \pm 0.10$ \\
7M3T-2.0 & $52.6 \pm 1.8$ & $0.42 \pm 0.09$ \\
5M5G & $66.9 \pm 2.0$ & $0.33 \pm 0.06$ \\
5M5G-0.9 & $71.5 \pm 1.2$ & $0.39 \pm 0.01$ \\
5M5G-2.0 & $70.2 \pm 0.9$ & $0.35 \pm 0.02$ \\
\hline
\end{tabular}
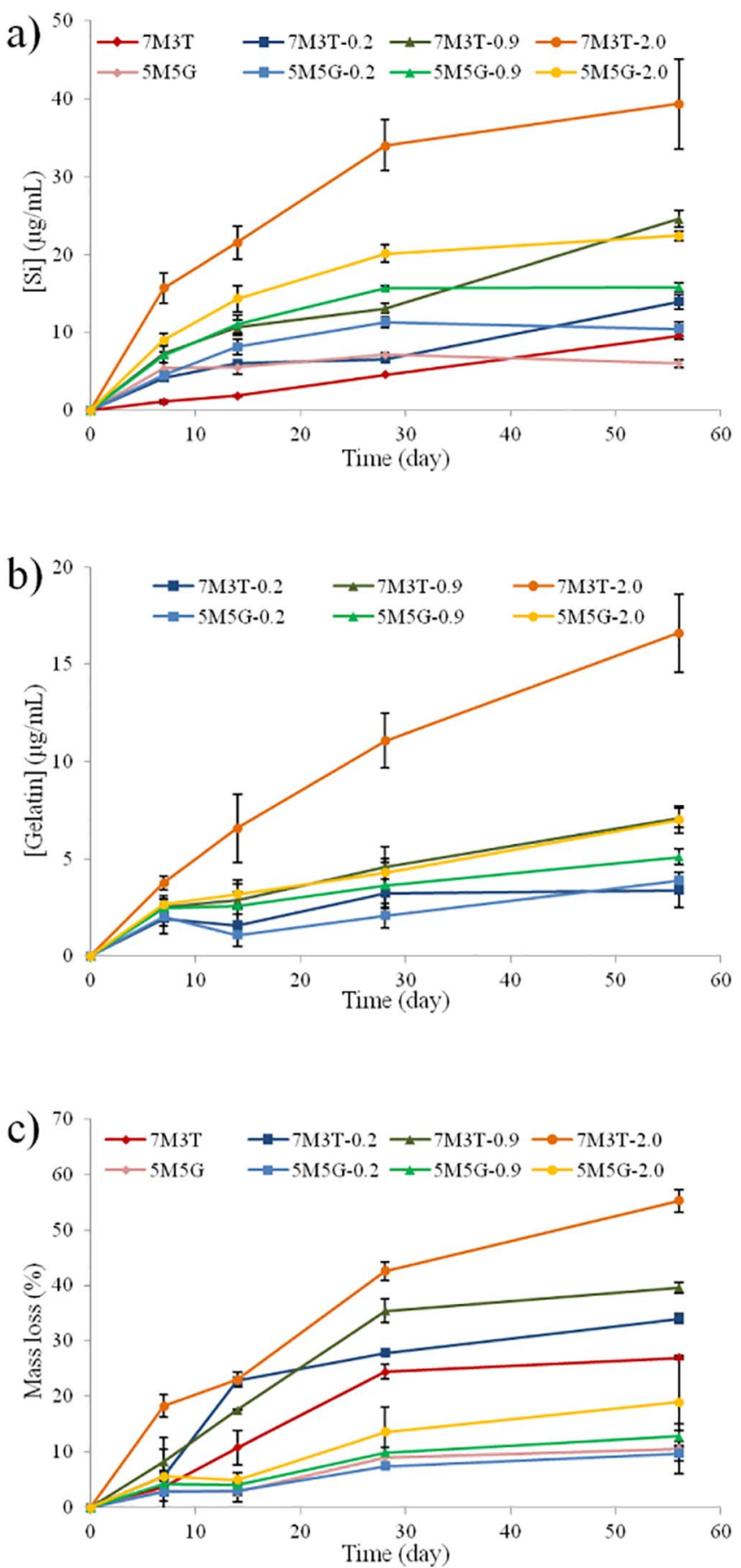

Fig. 6. The concentration of released $\mathrm{Si}$ (a) and gelatin (b) as a function of time of immersion in PBS solution, and the gravimetric study of the mass loss (c) due to the hydrolytic degradation. Lines are drawn as guide to show the tendency. introduction of GPTMS precursor into the structure of the network decreased the Ra value. The addition of gelatin slightly increased the Ra value from $0.33 \mathrm{~nm}$ for $5 \mathrm{M} 5 \mathrm{G}$ to 0.39 and $0.35 \mathrm{~nm}$ for $5 \mathrm{M} 5 \mathrm{G}-0.9$ and 5M5G-2.0, respectively.

\subsection{Dissolution study}

The silica-gelatin hybrid coatings degrade in the aqueous medium by undergoing a hydrolytic degradation, following the reaction described in Eq. (2). We examined the differences between the two types of silica matrixes and the effect of gelatin content on hybrid dissolution. Fig. 6 shows the curves for soluble Si (Fig. 6a), soluble gelatin (Fig. 6b) and mass loss (Fig. 6c). In all the cases, we observed a gradual dissolution of the materials immersed in PBS, and the extent of the degradation depended on the chemical composition of the hybrid.

The ICP results revealed that $\mathrm{Si}$ was released faster from 7M3T coating than from 5M5G; the Si concentration reached $10 \mu \mathrm{g} \cdot \mathrm{mL}^{-1}$ and $6 \mu \mathrm{g} \cdot \mathrm{mL}^{-1}$ after 8 weeks, respectively. However, the greatest differences were due to the introduction of gelatin into the silica network; the dissolution rate rose with increasing gelatin content. At the end of the experiment, 7M3T-2.0 hybrid released the highest amount of Si, $39 \mu \mathrm{g} \cdot \mathrm{mL}^{-1}$, almost double of the amount released by the homologous 5M5G-2.0 $\left(22 \mu \mathrm{g} \cdot \mathrm{mL}^{-1}\right)$. A similar trend was observed for the release of gelatin (Fig. 6b). 7M3T-0.2, 7M3T-0.9, and 7M3T-2.0 released larger amounts of this protein than 5M5G-0.2, 5M5G-0.9 and 5M5G-2.0 respectively. This behavior might be attributed to the chemical anchorage of gelatin to the siloxane network through the epoxy group. Furthermore, due to the weak interaction between 7M3T siloxane network and gelatin, and the high percentage of gelatin introduced, the 7M3T-2.0 hybrid had the highest dissolution rate, releasing $16 \mu \mathrm{g} \cdot \mathrm{mL}^{-1}$ of gelatin after 8 weeks. We observed an over two-fold increase in the dissolution rate for this hybrid in comparison with 5M5G-2.0 $\left(7 \mu \mathrm{g} \cdot \mathrm{mL}^{-1}\right)$ and 7M3T-0.9 $\left(7 \mu \mathrm{g} \cdot \mathrm{mL}^{-1}\right)$ and a three-fold increase in comparison with 5M5G-0.9 $\left(5 \mu \mathrm{g} \cdot \mathrm{mL}^{-1}\right)$. The 7M3T-2.0 dissolution rate was approximately 4 times higher than for 7M3T-0.2 $\left(4 \mu \mathrm{g} \cdot \mathrm{mL}^{-1}\right)$ and 5M5G-0.2 $\left(4 \mu \mathrm{g} \cdot \mathrm{mL}^{-1}\right)$.

Finally, the gravimetric study of the hydrolytic degradation (Fig. 6c) showed that the 7M3T coatings had higher degradability than 5M5G hybrids. The mass loss increased as the gelatin content increased, in all the cases. 5M5G and 5M5G-0.2 were the hybrids most stable in the aqueous media, with a similar degradation rate of approximately $10 \%$ of mass loss after 8 weeks. The 5M5G-0.9 and 5M5G-2.0 coatings showed similar values of 13 and $19 \%$, respectively. However, the 7M3T-gelatin hybrids showed higher mass losses. The 7M3T coating lost $27 \%$ of its mass after 56 days of incubation. The addition of different proportions of gelatin caused an increase in the dissolution rate. The weight loss reached $34 \%$ for $7 \mathrm{M} 3 \mathrm{~T}-0.2$ hybrid and $40 \%$ for $7 \mathrm{M} 3 \mathrm{~T}$ 0.9 , whereas the loss for 7M3T-2.0 composition increased 2-fold in comparison with 7M3T coating (55\%). The rate of dissolution is highly dependent on the chemical composition of the coating; both the selected alkoxysilane precursor matrix and the gelatin content affect this behavior.

\section{Discussion}

According to the spectra obtained using liquid-state ${ }^{29} \mathrm{Si}$ NMR (Figs. 1-3), the selected synthesis parameters were appropriate to carry out the sol-gel reaction to achieve the different $\mathrm{Si}$ species formation, and the heat treatment was necessary to obtain a cross-linked silica network (Fig. 4). Comparing the spectra in Fig. 2, we can confirm that the introduction of gelatin did not affect the formation of the Si-O-Si bonds since all the 7M3T-gelatin sols had the same structure after $2 \mathrm{~h}$ of reaction. Moreover, the analysis of peak areas for each film did not show significant differences between the condensation degrees of 7M3T and 7M3T-2.0 coatings ( 86.0 and $86.3 \%$, respectively). As expected, the connectivity of the network remains intact since gelatin is trapped by 
electrostatic and hydrogen bonding interactions between the residual nucleophilic groups in the gelatin chains and the siloxane matrix $[29,30]$. This interaction was also detected by IR spectroscopy (Fig. 5 spectra a and b). We observed that the band at $940 \mathrm{~cm}^{-1}$, corresponding to the stretching vibration of the silanol groups, was shifted to a lower wavenumber due to the formation of hydrogen bonds with the protein [29].

The results of the liquid-state ${ }^{29} \mathrm{Si}$ NMR showed significant differences between condensation degrees of the network in the 5M5G-gelatin hybrids after $2 \mathrm{~h}$ of reaction (Fig. 3). The most striking differences were those between the signal intensities corresponding to hydrolyzed GPTMS. In the case of the hybrid 5M5G without gelatin (spectrum a), the molecules condensed in different rates due to the absence of $\mathrm{T}_{\mathrm{M}}(\mathrm{OH})$ and $\mathrm{T}_{\mathrm{G}}(\mathrm{OH})$ species. In the case of hybrids with gelatin, however, the speed of reaction was slowed down and more molecules remained completely unbound after the sol-gel process (spectra $b$ to d). This behavior becomes more pronounced as gelatin content increases. Such results have been attributed to the covalent bonds created between the residual amino and carboxylic groups of gelatin and the epoxy group of GPTMS molecules [31,32]. The IR spectra $\mathrm{c}$ and $\mathrm{d}$ (Fig. 5) also revealed the formation of these bonds; there was a decrease in the intensity of the epoxide ring band at $900 \mathrm{~cm}^{-1}$. This behavior can be attributed to the ring opening and the possible subsequent reaction with the gelatin molecule [33].

Besides the chemical composition, the wettability and roughness are also important parameters of material intended for biomedical applications. The surface wettability is affected by the surface chemistry and topography $[34,35]$. The contact angle and roughness data (Table 3) show that a smooth, nanostructured, and moderately hydrophilic surfaces were obtained using the sol-gel method. These parameters determine the interaction of the developed materials with biological fluids; surfaces with contact angle below $90^{\circ}$ facilitate the interaction with the fluids and, hence, with serum proteins and cells [36,37]. The sol-gel hybrids with an intermediate hydrophilicity (contact angle of approximately $70^{\circ}$ ) have been reported to promote cell growth [38]. This is the hydrophilicity range found for the coatings developed in this study. Moreover, current trends in biomaterials include the design of surfaces with nanoscale topography. The production of this type of modification on an implant surface may contribute to the mimicry of cellular environments and appears to affect cell interactions [39,40]. The materials developed in this work showed surfaces with roughness values from 0.33 to 0.50 . Some previous works have reported the upregulation of genes involved in the osteoblastic differentiation in nanostructured surfaces $[39,41]$. The possibility of applying these coatings to metallic implants presents an opportunity to modulate cell response.

In the case of 7M3T hybrids, results show how the water contact angle value of gelatin modified coatings decreases successively compared to the blank 7M3T hybrid. The introduction of a small amount of gelatin, such as $2 \mathrm{wt} \%$, was enough to decrease this value from $70.0^{\circ}$ to $52.6^{\circ}$. This behavior is quite common for the films with hydrophilic proteins on its surface $[38,40]$. Comparing 5 M5G contact angle $\left(66,9^{\circ}\right)$ with 7M3T one a lower value was obtained, this is attributed to the decrease of the more hydrophobic MTMOS and the introduction of the more hydrophilic GPTMS [17]. Additionally, in the case of 5M5G hybrids the addition of gelatin caused a slight increase in the contact angle. This can be most likely due to the decrease in the number of nonbridging oxygen atoms after adding gelatin [42]; this means fewer silanol groups on the surface, as seen in the solid-state ${ }^{29} \mathrm{Si}$ NMR spectra and, consequently, a reduction in hydrophilicity.

These, and similar, hybrids might be employed as coatings for metallic implants or carriers of drugs and growth factors to be used as controlled release matrixes. Thus, it is extremely important to determine their degradability. Moreover, there is some evidence that $\mathrm{Si}$ affects bone regeneration by stimulating bone matrix synthesis, alkaline phosphatase activity, and osteoblastic differentiation and mineralization [38,43]. Both ICP (Fig. 6a) and BCA (Fig. 6b) assays revealed that the rate of dissolution was higher for 7M3T than for 5M5G coatings; this trend became more noticeable with the increase in the gelatin content. The protein chains are effectively anchored in the inorganic silica phase via GPTMS. As a result, 5M5G-gelatin hybrid forms the coating that is most stable in the aqueous media, releasing the smallest amounts of gelatin and Si. These results confirmed that we obtained a homogeneous hybrid network, where the cross-linking effect of GPTMS had an impact in both phases of the hybrid.

The gravimetric study of the siloxane-gelatin network dissolution (Fig. 6c) corroborated the behavior seen for the Si and gelatin release. The 7M3T coatings showed the highest weight losses, with and without gelatin. Some other studies have shown that the addition of TEOS increases the degradability of the hybrid $[25,44]$ as well as its porosity and water uptake [45]. Likewise, the physical entrapment of gelatin in the 7M3T siloxane network might increase the porosity, accelerating the dissolution of the coating. It also (as shown in Table 3) increased the hydrophilicity of the surface considerably, facilitating the interaction with water. Therefore, tunable dissolution properties can be obtained by varying the chemical composition of the silica phase and by modifying the protein retention mechanism.

\section{Conclusion}

We obtained homogeneous, strongly adherent, nanostructured coatings with substantial potential for biomedical applications. The obtained data indicate that these hybrid coatings with an initial low dissolution rate might provide an efficient initial protection for metallic implants. The ability of gelatin regulating cell adhesion and the osteoinduction properties of Si make these hybrids suitable as coatings for orthopedic and dental implants. Moreover, the performance of the hybrids and their tunable properties indicate that they are also suitable as delivery systems.

Our results showed that tailoring the in vitro dissolution rate of such materials might be realistic designing matrixes with different amounts of physically or chemically entrapped gelatin, depending on the final application. Further studies should be carried out to test their biological performance.

\section{Acknowledgement}

M. M-I. thanks the Basque Government (BFI-2011-183) for the financial support during this work (Pre-doctoral grant). This research project has been supported in part by the Ministerio de Economía y Competitividad (MAT2014-51918-C2-2R, Govern of Spain) and the University of the Basque Country (UFI 11/56; IT 611-13).

\section{References}

[1] M. Niinomi, Recent metallic materials for biomedical applications, Metall. Mater. Trans. A 33 (2002) 477-486, http://dx.doi.org/10.1007/s11661-002-0109-2.

[2] T. Hanawa, Overview of metals and applications, in: M. Niinomi (Ed.), Metals for Biomedical Devices, CRC Press, Florida, 2010, pp. 3-24, , http://dx.doi.org/10. 1533/9781845699246.1.3.

[3] D.A. Puleo, W.W. Huh, Acute toxicity of metal ions in cultures of osteogenic cells derived from bone marrow stromal cells, J. Appl. Biomater. 6 (1995) 109-116, http://dx.doi.org/10.1002/jab.770060205.

[4] H. Matusiewicz, Potential release of in vivo trace metals from metallic medical implants in the human body: from ions to nanoparticles - a systematic analytical review, Acta Biomater. 10 (2014) 2379-2403, http://dx.doi.org/10.1016/j.actbio. 2014.02.027.

[5] T. Wachi, T. Shuto, Y. Shinohara, Y. Matono, S. Makihira, Release of titanium ions from an implant surface and their effect on cytokine production related to alveolar bone resorption, Toxicology 327 (2015) 1-9, http://dx.doi.org/10.1016/j.tox. 2014.10.016.

[6] J.L. Ong, D.L. Carnes, K. Bessho, Evaluation of titanium plasma-sprayed and plasma-sprayed hydroxyapatite implants in vivo, Biomaterials 25 (2004) 4601-4606, http://dx.doi.org/10.1016/j.biomaterials.2003.11.053.

[7] L. Le Guéhennec, A. Soueidan, P. Layrolle, Y. Amoiuriq, Surface treatments of titanium dental implants for rapid osseointegration, Dent. Mater. 23 (2007) 844-854, http://dx.doi.org/10.1016/j.dental.2006.06.025. 
[8] X. Chen, Y. Li, P.D. Hodgson, C. Wen, Microstructures and bond strengths of the calcium phosphate coatings formed on titanium from different simulated body fluids, Mater. Sci. Eng. C 29 (2009) 165-171, http://dx.doi.org/10.1016/j.msec. 2008.06.004.

[9] P.G. Coelho, J.M. Granjeiro, G.E. Romanos, M. Suzuki, N.R. Silva, G. Cardaropoli, V.P. Thompson, J.E. Lemons, Basic research methods and current trends of dental implant surfaces, J Biomed Mater Res B Appl Biomater 88 (2009) 579-596, http:// dx.doi.org/10.1002/jbm.b.31264.

[10] A. Durán, Y. Castro, M. Aparicio, A. Conde, J.J. Damborenea, Protection and surface modification of metals with sol-gel coatings, J. Int. Mat. Rev. 52 (2007) 174-192, http://dx.doi.org/10.1179/174328007X160263.

[11] D. Balgude, A. Sabnis, Sol-gel derived hybrid coatings as an environment friendly surface treatment for corrosion protection of meals and their alloys, J. Sol-Gel Sci. Technol. 64 (2012) 124-134, http://dx.doi.org/10.1007/s10971-012-2838-z.

[12] P. Wojciechowska, P. Pietras, H. Maciejewski, Synthesis, characterization, and thermal properties of organic-inorganic hybrids based on gelatin and organomodified silicones, Adv. Polym. Technol. 33 (2014) S1-21459, http://dx.doi.org/10 1002/adv.21459.

[13] C.A. Milea, C. Bogatu, A. Duta, The influence of parameters in silica sol-gel process, Bull. Transyl. Univ. Braşov. 4 (2011) 59-66.

[14] D. Wang, G.P. Bierwagen, Sol-gel coatings on metals for corrosion protection, Prog. Org. Coat. 64 (2009) 327-338, http://dx.doi.org/10.1016/j.porgcoat.2008.08.010.

[15] K. Tsuru, Z. Robertson, B. Annaz, I.R. Gibson, S.M. Best, Y. Shirosaki, S. Hayakawa, A. Osaka, Sol-gel synthesis and in vitro cell compatibility analysis of silicate-containing biodegradable hybrid gels, Key Eng. Mater. 361 (2008) 447-450, http://dx. doi.org/10.4028/www.scientific.net/KEM.361-363.447.

[16] A. Beganskiene, R. Raudonis, S.Z. Jokhadar, U. Batista, A. Kareiva, Modified sol-gel coatings for biotechnological applications, J. Phys. Conf. Ser. 93 (2007) 1-6, http:// dx.doi.org/10.1088/1742-6596/93/1/012050.

[17] M.J. Juan-Díaz, M. Martínez-Ibáñez, I. Lara-Sáez, S. da Silva, R. Izquierdo, M. Gurruchaga, I. Goñi, J. Suay, Development of hybrid sol-gel coatings for the improvement of metallic biomaterials performance, Prog. Org. Coat. 96 (2016) 42-51, http://dx.doi.org/10.1016/j.porgcoat.2016.01.019.

[18] M. Martínez-Ibáñez, M.J. Juan-Díaz, I. Lara-Saez, A. Coso, J. Franco, M. Gurruchaga, J. Suay, I. Goñi, Biological characterization of a new silicon based coating developed for dental implants, J. Mater. Sci. Mater. Med. 27 (2016) 1-9, http://dx.doi.org/10.1007/s10856-016-5690-9.

[19] Y. Hu, L. Liu, Z. Gu, W. Dan, X. Yu, Modification of collagen with a natural derived cross-linker, alginate dialdehyde, Carbohydr. Polym. 102 (2014) 324-332, http:// dx.doi.org/10.1016/j.carbpol.2013.11.050.

[20] O. Mahony, O. Tsigkou, C. Ionescu, C. Minelli, L. Ling, R. Hanly, M.E. Smith, M.M. Stevens, J.R. Jones, Silica-gelatin hybrids with tailorable degradation and mechanical properties for tissue regeneration, Adv. Funct. Mater. 20 (2010) 3835-3845, http://dx.doi.org/10.1002/adfm.201000838.

[21] K.S. Lim, M.H. Alves, L.A. Poole-Warren, P.J. Martens, Covalent incorporation of non-chemically modified gelatin into degradable PVA-tyramine hydrogels, Biomaterials 34 (2013) 7097-7105, http://dx.doi.org/10.1016/j.biomaterials. 2013.06.005.

[22] C. Shi, W. Yuan, M. Khan, Q. Li, F. Yao, W. Zhang, Hydrophilic PCU scaffolds prepared by grafting PEGMA and immobilizing gelatin to enhance cell adhesion and proliferation, Mater. Sci. Eng. C 50 (2015) 201-209, http://dx.doi.org/10.1016/j. msec.2015.02.015.

[23] M. Martinez-Ibáñez, S. Murthy, Y. Mao, J. Suay, M. Gurruchaga, I. Goñi, A. Coso, J. Kohn, Effects of functionalized siloxane-gelatin hybrid coatings on the protein adsorption and osteogenic differentiation of hMSC, Clin. Oral Implants Res. 2 (2015) 49, http://dx.doi.org/10.1111/clr.46_12678.

[24] M. Martínez-Ibáñez, N.S. Murthy, Y. Mao, J. Suay, M. Gurruchaga, I. Goñi, J. Kohn, Enhancement of plasma protein adsorption and osteogenesis of hMSCs by functionalized siloxane coatings for titanium implants, J Biomed Mater Res B Appl Biomater (2015), http://dx.doi.org/10.1002/jbm.b.33889.

[25] M.J. Juan-Díaz, M. Martínez-Ibáñez, M. Hernández-Escolano, L. Cabedo, R. Izquierdo, J. Suay, M. Gurruchaga, I. Goñi, Study of the degradation of hybrid sol-gel coatings in aqueous medium, Prog. Org. Coat. 77 (2014) 1799-1806, http:// dx.doi.org/10.1016/j.porgcoat.2014.06.004.

[26] M. Zaharescu, A. Jitianu, A. Braileanu, J. Madarász, G. Pokol, Ageing effect on the $\mathrm{SiO}_{2}$-based inorganic-organic hybrid materials, J. Therm. Anal. Calorim. 64 (2001)
689-696, http://dx.doi.org/10.1023/A:1011536209930.

[27] M. Zaharescu, A. Jitianu, A. Brăileanu, J. Madarász, C.S. Novák, G. Pokol, Composition and thermal stability of $\mathrm{SiO}_{2}$-based hybrid materials TEOS-MTEOS system, J. Therm. Anal. Calorim. 71 (2003) 421-428, http://dx.doi.org/10.1023/ A:1022883221776.

[28] C.M. Bertelsen, F.J. Boerio, Linking mechanical properties of silanes to their chemical structure: an analytical study of $\gamma$-GPS solutions and films, Prog. Org. Coat. 41 (2001) 239-246, http://dx.doi.org/10.1016/S0300-9440(01)00135-7.

[29] T. Coradin, S. Bah, J. Livage, Gelatine/silicate interactions: from nanoparticles to composite gels, Colloids Surf. B: Biointerfaces 35 (2004) 53-58, http://dx.doi.org/ 10.1016/j.colsurfb.2004.02.008.

[30] S. Smitha, P. Mukundan, P. Krishna Pillai, K.G.K. Warrier, Silica-gelatin bio-hybrid and transparent nano-coatings through sol-gel technique, Mater. Chem. Phys. 103 (2007) 318-322, http://dx.doi.org/10.1016/j.matchemphys.2007.02.068.

[31] B. Yoon, H.E. Kim, H.W. Kim, Bioactive microspheres produced from gelatin-siloxane hybrids for bone regeneration, J. Mater. Sci. Mater. Med. 19 (2008) 2287-2292, http://dx.doi.org/10.1007/s10856-007-3332-y.

[32] O. Mahony, S. Yue, C. Turdean-Ionescu, J.V. Hanna, M.E. Smith, P.D. Lee, J.R. Jones, Silica-gelatin hybrids for tissue regeneration: inter-relationships between the process variables, J. Sol-Gel Sci. Technol. 69 (2014) 288-298, http://dx. doi.org/10.1007/s10971-013-3214-3.

[33] P. Innocenzi, G. Brusatin, M. Guglielmi, R. Bertani, New synthetic route to (3-glycidoxypropyl) trimethoxysilane-based hybrid organic-inorganic materials, Chem. Mater. 11 (1999) 1672-1679, http://dx.doi.org/10.1021/cm980734z.

[34] S.J. Hitchcock, N.T. Carroll, M.G. Nicholas, Some effects of substrate roughness on wettability, J. Mater. Sci. 1 (1981) 714-732, http://dx.doi.org/10.1007/ BF00552210.

[35] H.P. Felgueiras, N.S. Murthy, S.D. Sommerfeld, M.M. Brás, V. Migonney, J. Kohn, Competitive adsorption of plasma proteins using a quartz crystal microbalance, ACS Appl. Mater. Interfaces 8 (2016) 13207-13217, http://dx.doi.org/10.1021/acsami. 5 b12600.

[36] F. Rupp, R.A. Gittens, L. Scheideler, A. Marmur, B.D. Boyan, Z. Schwartz, J. GeisGestorfer, A review on the wettability of dental implant surfaces I: theoretical and experimental aspects, Acta Biomater. 10 (2014) 2894-2906, http://dx.doi.org/10. 1016/j.actbio.2014.02.040.

[37] R.A. Gittens, L. Scheideler, F. Rupp, S.L. Hyzy, J. Geis-Gerstofer, Z. Schwartz, B.D. Boyan, A review on the wettability of dental implant surfaces II: biological and clinical aspects, Acta Biomater. 10 (2014) 2907-2918, http://dx.doi.org/10.1016/ j.actbio.2014.03.032.

[38] C. Zolkov, D. Avnir, R. Armon, Tissue-derived cell growth on hybrid sol-gel films, J. Mater. Chem. 14 (2004) 2200-2205, http://dx.doi.org/10.1039/B401715N.

[39] G. Mendonça, D.B. Mendonça, F.J. Aragao, L.F. Cooper, Advancing dental implant surface technology-from micron-to nanotopography, Biomaterials 29 (2008) 3822-3835, http://dx.doi.org/10.1016/j.biomaterials.2008.05.012.

[40] F. Gentile, L. Tirinato, E. Battista, F. Causa, C. Liberale, E.M. di Fabrizio, P. Decuzzi, Cells preferentially grow on rough substrates, Biomaterials 31 (2010) 7205-7212, http://dx.doi.org/10.1016/j.biomaterials.2010.06.016.

[41] Z.M. Isa, G.B. Schneider, R. Zaharias, D. Seabold, C.M. Stanford, Effects of fluoridemodified titanium surfaces on osteoblast proliferation and gene expression, Int. J. Oral Maxillofac. Implants 21 (2006) 203-211.

[42] S. Van Vlierberghe, E. Vanderleyden, V. Boterberg, P. Dubruel, Gelatin functionalization of biomaterial surfaces: strategies for immobilization and visualization, Polymer 3 (2011) 114-130, http://dx.doi.org/10.3390/polym3010114.

[43] Y. Shirosaki, K. Tsuru, S. Hayakawa, Y. Nakamura, I.R. Gibson, A. Osaka, Effects of $\mathrm{Si}(\mathrm{IV})$ released from chitosan-silicate hybrids on proliferation and differentiation of MG63 osteoblast cells, Bioceram. Dev. Appl. 1 (2011) 1-4, http://dx.doi.org/10. 4303/bda/D110112.

[44] F. Romero-Gavilán, S. Barros-Silva, J. García-Cañadas, B. Palla, R. Izquierdo, M. Gurruchaga, I. Goñi, J. Suay, Control of the degradation of silica sol-gel hybrid coatings for metal implants prepared by the triple combination of alkoxysilanes, J. Non-Cryst. Solids 453 (2016) 66-73, http://dx.doi.org/10.1016/j.jnoncrysol.2016. 09.026.

[45] C. Shi, W. Yuan, M. Khan, Q. Li, Y. Feng, F. Yao, W. Zhang, Hydrophilic PCU scaffolds prepared by grafting PEGMA and immobilizing gelatin to enhance cell adhesion and proliferation, Mater. Sci. Eng. C 50 (2015) 201-209, http://dx.doi. org/10.1016/j.msec.2015.02.015. 